\title{
An unusual trackway of a possibly bipedal archosaur from the Late Triassic of the Sichuan Basin, China
}

Lida Xing, Guangzhao Peng, Daniel Marty, Yong Ye, Hendrik Klein, Jianjun Li, Gerard D. Gierliński, and Chunkang Shu

Acta Palaeontologica Polonica 59 (4), 2014: 863-871 doi: http://dx.doi.org/10.4202/app.2012.0087

The Longguan dinosaur tracksite in the Sichuan Basin (China) is described. It is located in the uppermost part of the Upper Triassic Xujiahe Formation and displays a single, unusual trackway consisting of 19 deeply impressed pes imprints. All tracks have suffered from erosion over many years of exposure, but they still reveal interesting details such as conspicuous elongated grooves, interpreted here as toe and claw drag marks. The trackmaker, a medium-sized archosaur, was walking in a thick and relatively soft layer of sand. The elongated, oval shape of the footprints resembles the ichnogenus Eosauropus from North America and Europe, assigned to facultative bipedal sauropodomorphs. The Chinese track differs by inward rotation of the footprints toward the midline, whereas in Eosauropus, these are turned strictly outward. Other ichnotaxa and possible trackmakers are discussed, but presently, a distinct assignment cannot be given. The Longguan trackway enlarges the scarce footprint record from the Triassic of China.

Key words: Vertebrate ichnology, archosaur trackway, deep tracks, Triassic, Xujiahe Formation, Sichuan Province, China.

Lida Xing [xinglida@gmail.com], Department of Biological Sciences, University of Alberta,11455 Saskatchewan Drive, Edmonton, Alberta T6G 2E9, Canada; Guangzhao Peng [pguangzhao@yahoo.com.cn], Yong Ye [yeyozdm@126.com ], and Chunkang Shu [sckang@yahoo.cn], Zigong Dinosaur Museum, Zigong 643013, Sichuan, China; Daniel Marty [daniel.marty@ palaeojura.ch ], Office de la Culture-Paléontologie A16, Hôtel des Halles, P.O. Box 64, 2900 Porrentruy 2, Switzerland; Hendrik Klein [Hendrik.Klein@combyphone.eu], Saurierwelt Paläontologisches Museum, Alte Richt 7, D-92318 Neumarkt, Germany; Jianjun Li [1jj5681@126.com], Department of Paleontology, Beijing Natural History Museum, 126 Tian Qiao South Street, Beijing 100050, China; Gerard D. Gierliński [gierlinski@yahoo.com], JuraPark, ul. Sandomierska 4, 27-400 Ostrowiec Świętokrzyski, Poland, and Polish Geological Institute, Rakowiecka 4, 00-975 Warszawa, Poland. 
This is an open-access article distributed under the terms of the Creative Commons

Attribution License (for details please see creativecommons.org), which permits unrestricted use, distribution, and reproduction in any medium, provided the original author and source are credited.

Forill text $(766.2 \mathrm{kB})$ 